\title{
Correction: MYCN acts as a direct co-regulator of p53 in MYCN amplified neuroblastoma
}

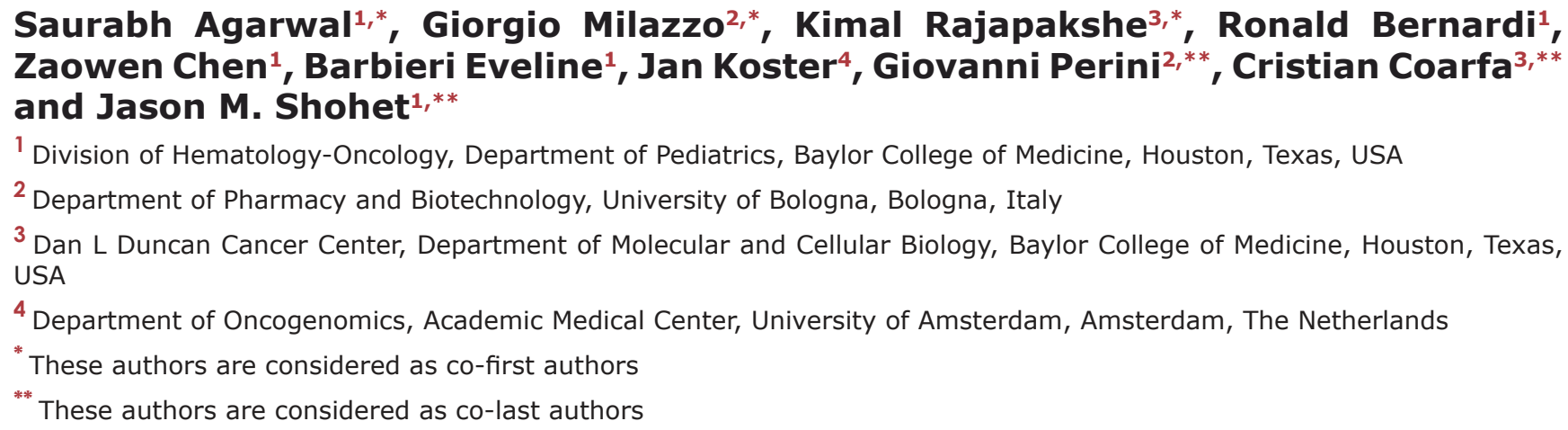
Zaowen Chen ${ }^{1}$, Barbieri Eveline ${ }^{1}$, Jan Koster ${ }^{4}$, Giovanni Perini ${ }^{2, * *}$, Cristian Coarfa ${ }^{3, * *}$ and Jason M. Shohet ${ }^{1, * *}$

${ }^{1}$ Division of Hematology-Oncology, Department of Pediatrics, Baylor College of Medicine, Houston, Texas, USA

2 Department of Pharmacy and Biotechnology, University of Bologna, Bologna, Italy

${ }^{3}$ Dan L Duncan Cancer Center, Department of Molecular and Cellular Biology, Baylor College of Medicine, Houston, Texas, USA

${ }^{4}$ Department of Oncogenomics, Academic Medical Center, University of Amsterdam, Amsterdam, The Netherlands

* These authors are considered as co-first authors

** These authors are considered as co-last authors

Published: July 06, 2018

Copyright: Agarwal et al. This is an open-access article distributed under the terms of the Creative Commons Attribution License 3.0 (CC BY 3.0), which permits unrestricted use, distribution, and reproduction in any medium, provided the original author and source are credited.

This article has been corrected: The corrected author name is given below:

\section{Barbieri Eveline}

Original article: Oncotarget. 2018; 9:20323-20338. https://doi.org/10.18632/oncotarget.24859 